DOE/ER/62189-5

\title{
MOLECULAR MEDICINE: SYNTHESIS AND IN VIVO DETECTION OF AGENTS FOR USE IN BORON NEUTRON CAPTURE THERAPY
}

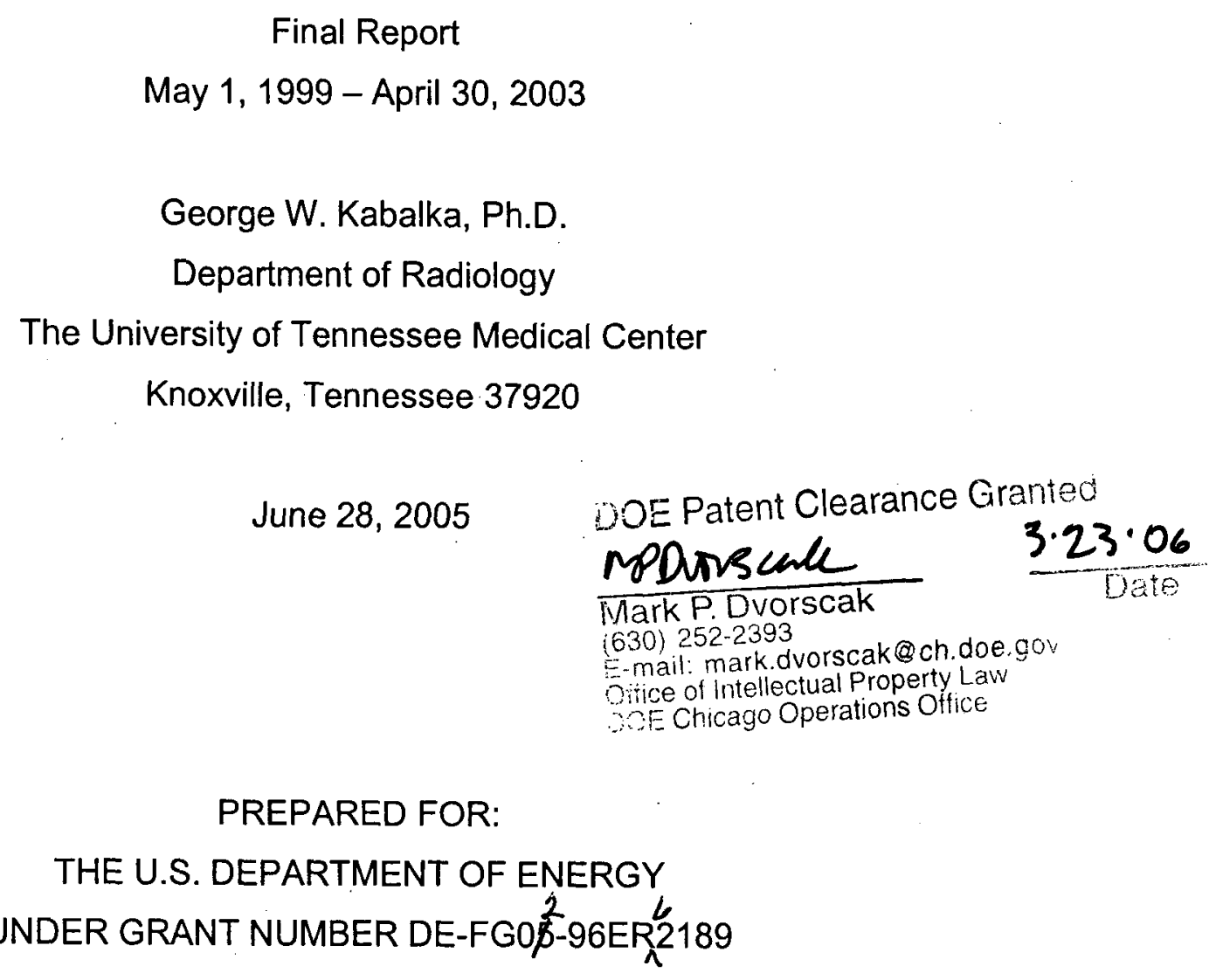




\section{DISCLAIMER}

This report was prepared as an account of work sponsored by an agency of the United States Government. Neither the United States Government nor any agency Thereof, nor any of their employees, makes any warranty, express or implied, or assumes any legal liability or responsibility for the accuracy, completeness, or usefulness of any information, apparatus, product, or process disclosed, or represents that its use would not infringe privately owned rights. Reference herein to any specific commercial product, process, or service by trade name, trademark, manufacturer, or otherwise does not necessarily constitute or imply its endorsement, recommendation, or favoring by the United States Government or any agency thereof. The views and opinions of authors expressed herein do not necessarily state or reflect those of the United States Government or any agency thereof. 


\section{DISCLAIMER}

Portions of this document may be illegible in electronic image products. Images are produced from the best available original document. 


\section{TABLE OF CONTENTS}

\section{OBJECTIVE}

II. RESEARCH ACCOMPLISHMENTS
A. Dosimetry Calculations
B. New Agents

III. BIBLIOGRAPHY OF DOE PUBLICATIONS
A. Journal Articles
B. Research Presentations
C. Invited Lectures

IV. GRADUATE AND POSTDOCTORAL STUDENTS
A. Postdoctoral Students
B. Graduate Students
C. Undergraduate Students

\section{REFERENCES}




\section{OBJECTIVE}

The primary objective of the D.O.E. program at The University of Tennessee Medical Center is the development of in vivo methods for the detection and evaluation of tumors in humans. During this three-year period, we focused on utilizing positron emission tomography (PET) to monitor the distribution and pharmacokinetics of a current BNCT agent, $p$-boronophenylalanine (BPA) by labeling it with a fluorine-18, a positron emitting isotope. The PET data was then used to develop enhanced treatment planning protocols. The study also involved the synthesis of new tumor selective BNCT agents that could be labeled with radioactive nuclides for the in vivo detection of boron.

During the initial phase of this study we synthesized the fructose complex of a fluorinated analogue of BPA and carried out PET biodistribution studies in glioblastoma multiforme patients who were then treated by BNCT at either Brookhaven National Laboratory or at The Massachusetts Institute of Technology in collaboration with Harvard Medical School. We were able to utilize the in vivo biodistribution data of para-boronophenylalanine labeled with fluorine-18 to develop enhanced PET based dosimetry calculations that more accurately matched clinical outcomes. During the next phase of the program we propose investigate the use of fluorine-18 labeled PET as a general tumor imaging agent and to train students in the scientific aspects of nuclear medicine. 


\section{RESEARCH ACCOMPLISHMENTS}

I am pleased to report that this has been a productive period for the D.O.E. BNCT Program at The University of Tennessee. Twenty-five articles and book chapters have resulted from this research. Thirty-nine referred research abstracts of presentations have also been published. I was invited to present lectures at nineteen universities and scientific meetings. In addition, six postdoctoral students as well as twenty graduate and undergraduate students received training.

\section{A. Dosimetry Calculations}

The fructose complex of fluorine-18 labeled $p$-boronophenylalanine, ${ }^{18} \mathrm{~F}$-BPA-F (1), an analogue of the agent currently being used in BNCT was first prepared in our laboratories, used to image brain tumor patients, and utilized to generate new BNCT<smiles>NC(Cc1ccc([18OH])cc1Br)C(=O)O</smiles>

1

treatment plans. A representative PET scan of a glioblastoma multiforme (GBM) patient is shown in Figure 1. It reveals an area of intense uptake in the right posterior parietal region that corresponds to the location of the lesion as seen on CT and MRI, Figure 1 (next page). 


\section{Pre-operative}

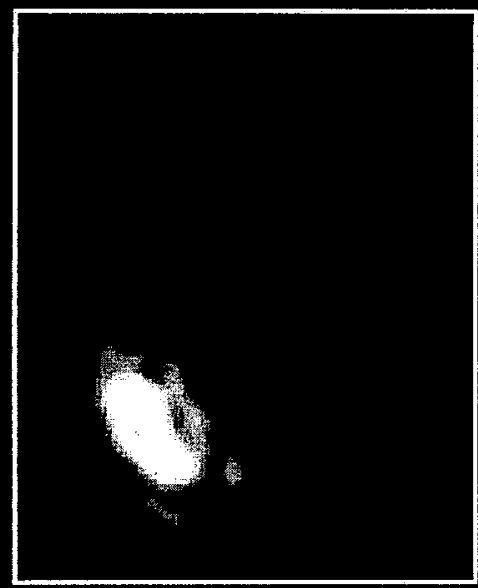

Transaxial

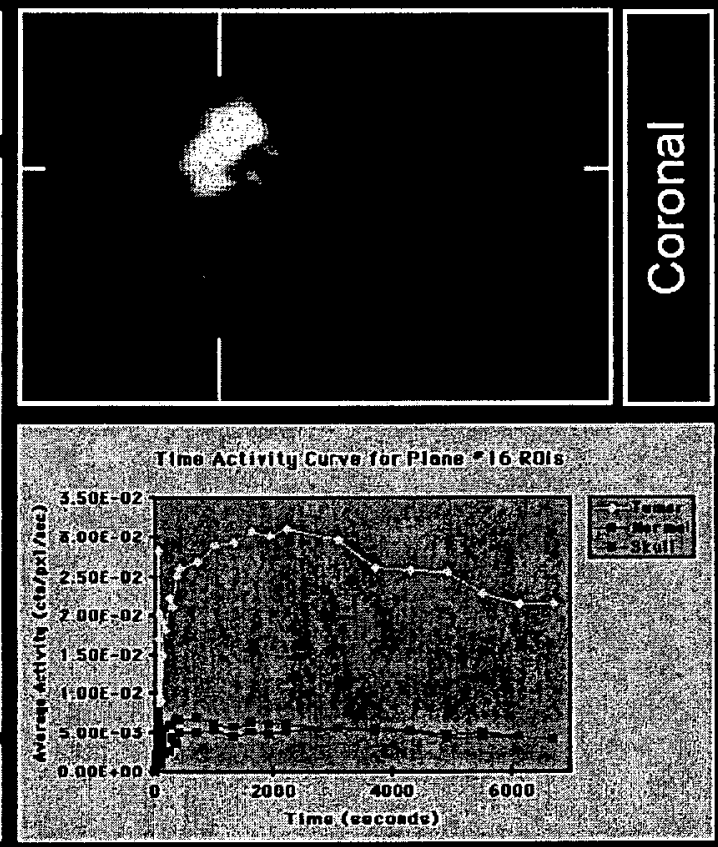

Figure 1. Pre-operative PET Scan and uptake curves of a Glioblastoma Patient. The time activity curve demonstrates selective uptake in the tumor as compared to normal brain tissue. At 52 minutes post injection, the ratio of tumor:brain activity was approximately 3.1 .

The patient underwent two additional PET studies using ${ }^{18} \mathrm{~F}-\mathrm{BPA}-\mathrm{F}$. The first was carried out six weeks post craniotomy and showed residual focal uptake in the medial portion of the original tumor, corresponding to a site of known remaining tumor as confirmed by the neurosurgeon.

Traditional treatment planning for BNCT is carried out using computed tomography (CT) or magnetic resonance imaging (MRI) to delineate the tumor from the surrounding tissues. ${ }^{1,2,3,4,5}$ In the case of GBM, the scalp, skull, normal brain, tumor, and $2 \mathrm{~cm}$ target regions around the tumor $(1-3 \mathrm{~cm})$ are typically demarcated for treatment planning. White matter, dark matter, and cerebral structures are not typically demarcated for treatment planning purposes. GBM cannot be demarcated even though CT and MRI images appear to possess distinct tumor boundaries since the tumor is infiltrative in nature. To address this problem, whenever possible in the trials at Brookhaven National Laboratory, a patient with a GBM was given an intravenous 
loading dose of BPA prior to neurosurgical debulking. Some of the pathological specimens obtained by the neurosurgeon were analyzed to determine the boron concentrations. This technique does provide accurate, but limited, boron concentrations for the tumor and, in some cases, a few areas immediately bordering the tumor. The boron distribution data so obtained is averaged to provide a constant value for the dose calculations, i.e. a homogeneous boron distribution in the tumor is assumed. Aside from PET data obtained using ${ }^{18} \mathrm{~F}-\mathrm{BPA}$ described earlier, there exists little information about the boron distribution in post surgical and post BNCT GBM patients.

Positron emission tomograms can be obtained that qualitatively and quantitatively represent the boron distribution in vivo by fluorinating BPA with fluorine18. ${ }^{6,7,8,9}$ Since ${ }^{18} \mathrm{~F}$-BPA is not metabolized in vivo, PET tomograms should reflect the actual boron distribution in a given patient. ${ }^{10}$ We utilized PET scans to provide three dimensional boron distribution maps, that were then used for macroscopic dose calculations in conventional neutron transport codes such as the SERA code developed at the Idaho National Engineering and Environmental Laboratory (INEEL).

SERA is a modification of traditional Monte-Carlo based neutron transport codes that calculate the dose from the $(n, \alpha),(n, \alpha \gamma)$, and $(n, p)$ reactions and has modifications that make it especially suited for BNCT. ${ }^{11}$ Because the majority of the micro-dose $(\sim 65 \%)$ derives from the ${ }^{10} \mathrm{~B}(\mathrm{n}, \alpha)^{7} \mathrm{Li}$ reaction, the distribution of boron determines the major variability in the macro-dose.

In this study, ${ }^{18} \mathrm{~F}$-BPA-fructose was prepared and then administered to each patient who received $\sim 370 \mathrm{mBq}(10 \mathrm{mCi})$ of the ${ }^{18} \mathrm{~F}$-BPA-fructose. PET scans were acquired on an ECAT EXACT 921 whole-body PET system (Siemens/CTI, Knoxville, TN) that produces 47 image slices over a $16.2 \mathrm{~cm}$ axial field of view. Dynamic emission images were acquired using twelve $10 \mathrm{sec}$ frames, five $60 \mathrm{sec}$ frames, and six $5 \mathrm{~min}$ frames, followed by $10 \mathrm{~min}$ frames up to $2 \mathrm{hr}$ post injection. The actual time in the PET scanner was determined by the patient's ability to tolerate lying on the gantry. All images were reconstructed using measured attenuation correction with filtered backprojection, a zoom factor of 2 , and a 0.35 pixel $^{-1}$ Hann filter. In order to avoid problems due to patient orientation in the scanner, treatment plans were 
performed using only the PET images. The boron distribution then was used to linearly scale the treatment plan as described below. This technique eliminated co-registration problems that arise when MRI and PET images are both used in planning.

The dose calculations were obtained using the code, SERA, developed at the Idaho National Engineering and Environmental Laboratory (INEEL) in conjunction with Montana State University. ${ }^{1,2}$ The definition of structures was accomplished with SERA using PET images. The code generates neutron tracts and interactions in a user defined nuclear species environment. SERA was used to process the PET images by delineating the tumor and various other cerebral structures in parallel planes which resulted in a three-dimensional map of the scalp, skull, normal brain, and tumor. The neutron transport calculations were then run for the nuclear species commonly found in the body at normal concentrations with ${ }^{10} \mathrm{~B}$ being defined everywhere as $1.0 \mathrm{ppm}$. The isodose contours initially generated reflect the dose due to the neutrons reacting with normal body composition of nuclear species and a constant homogeneous ${ }^{10} \mathrm{~B}$ distribution. Boron information was used as a post-processing linear scale factor for the isodose contours generated by SERA. In the case of current treatment planning, the ${ }^{10} \mathrm{~B}$ was input as a constant homogeneous value for the normal brain with the tumor being a three dimensional step function that is 3.5-4.5 times that of the normal brain. In this study, a ratio of 3.5:1 was used in these calculations, as is usually done clinically, that corresponds to $45.5 \mathrm{ppm}$ and $13 \mathrm{ppm}$ tumor to normal tissue respectively. Since the maximal ${ }^{10} \mathrm{~B}$ measured in a GBM to date has been found to be no larger than $\sim 50$ ppm, a linear post-processing method has been shown to be adequate to calculate correct doses. SERA was run with the geometries determined by PET scans to select the optimal beam direction to obtain the maximum neutron fluence to the tumor and the surrounding edema. The isodose contours produced by SERA were then scaled by a three dimensional step function at the site of the tumor with the boron concentration 4.5 times that of the surrounding tissue to produce conventional treatment plans (though based on PET scans). The output of SERA was then scaled with the PET data containing all boron concentrations (which incorporates the inhomogenieties) to construct the new isodose contours. Both sets of isodose curves were compared both 
analytically and visually. The planes chosen were determined visually to be the planes with largest tumor area (i.e. approximately the centroid of the tumor).

The data from six patients with glioblastoma multiforme were analyzed. The dynamic scans were plotted and compared with the simultaneously measured activity from venous sampling. In all cases, the boron levels in blood and normal brain tissue (i.e. greater than $3 \mathrm{~cm}$ from the center of the tumor) levels peaked within 1-3 min and fell off in approximately $8 \mathrm{~min}$ in an exponential decline. The tumor (measured at the center) boron levels rose quickly in the first $5 \mathrm{~min}$ and then fell off gradually from rather flat peak at approximately $40 \mathrm{~min}$. The time activity curves obtained for a two hour period indicate that the optimal time to treat is $-40-60 \mathrm{~min}$ after the initial infusion (which is approximately the time frame used in the clinical trials).

Treatment plans were generated using the ${ }^{18} \mathrm{~F}$-BPA-PET scan images and SERA. The output from SERA represents the statistical solution of the Boltzmann transport equation for neutrons in the normal brain with a homogeneous distribution of $\sim 13 \mathrm{ppm}$ boron. The resulting isodose contours were qualitatively similar to those obtained using computed tomography (CT) or magnetic resonance (MR) images to generate the isodose contours. The isodose contours were then scaled with the standard assumption of the boron concentration being a homogeneous three dimensional step function. The boron to normal brain tissue ratio was taken to be $4: 1$ as in the standard model. A second set of isodose contours was then generated by taking the SERA output and scaling it by the boron concentrations determined by the ${ }^{18}$ F-BPA-PET PET images. Representative examples for two patients are presented in Figure 2. 

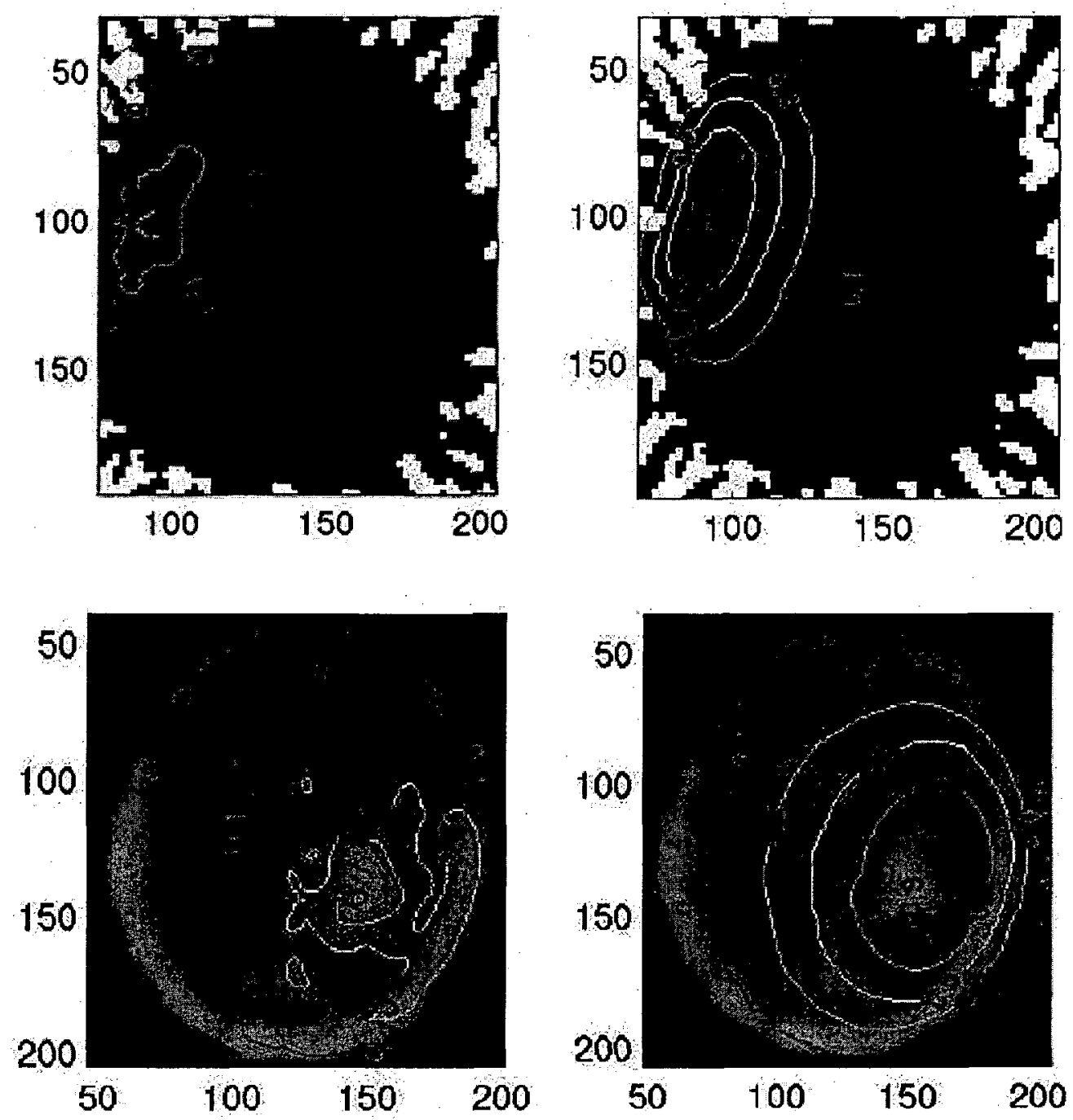

Figure 2: $\quad$ Two patients with PET scaled isodose curves (on the left) and standard curves on the right.

Although the planes chosen shown are visually ones with largest tumor area, the results were found to be similar in other planes. Qualitatively, the isodose contours based upon the PET data are smaller and less regular than are those seen using the conventional calculations. The two methods of calculating the dose reveal differences that are easily identified by examining the percent difference columns that is calculated by dividing the isodose area calculated by the ${ }^{18} \mathrm{~F}$-BPA boron concentrations by the 
area generated using conventional methods with the resulting quotient being multiplied by one hundred.

Figure 3 (next page) contains serial MRI images of a patient immediately after surgery (3A), $\sim 2$ weeks after surgery (3B), $\sim 1$ month after BNCT $(3 \mathrm{C})$, and $\sim 6$ weeks after BNCT. The corresponding PET generated treatment plan indicated that the tumor would be destroyed but that the edematous tissue surrounding the main tumor would not likely receive a lethal dose. These images clearly reveal residual tumor shown later by PET to be metabolically active. Thus, the clinical findings parallel the PET derived treatment plan. In the other patients studied, the recurrences occurred locally in the edematous tissue region - tumor edge region. These findings are in agreement with the experience from the BNCT clinical trials at Brookhaven National Laboratory that showed the usual recurrence was local in nature rather than distant. ${ }^{12}$

The PET derived isodose contours correspond more closely to the observed BNCT clinical results than do the isodose contours generated by conventional calculations. This is important since these contours are used for treatment planning designed to eliminate the entire tumor, including the infiltrative portions, and not just the primary tumor mass. The lack of homogeneity in the tumor region, as well as in the surrounding tissues, leads to significant differences in dose calculations. Since the majority of the dose comes from the ${ }^{10} \mathrm{~B}(n, \alpha)^{7} \mathrm{Li}$ reaction, the resulting isodose contours must be at least qualitatively similar to the actual ${ }^{10} \mathrm{~B}$ distribution. The inhomogeneities seen in the PET images correspond much more closely to reality than the current assumption of homogeneous distributions. 

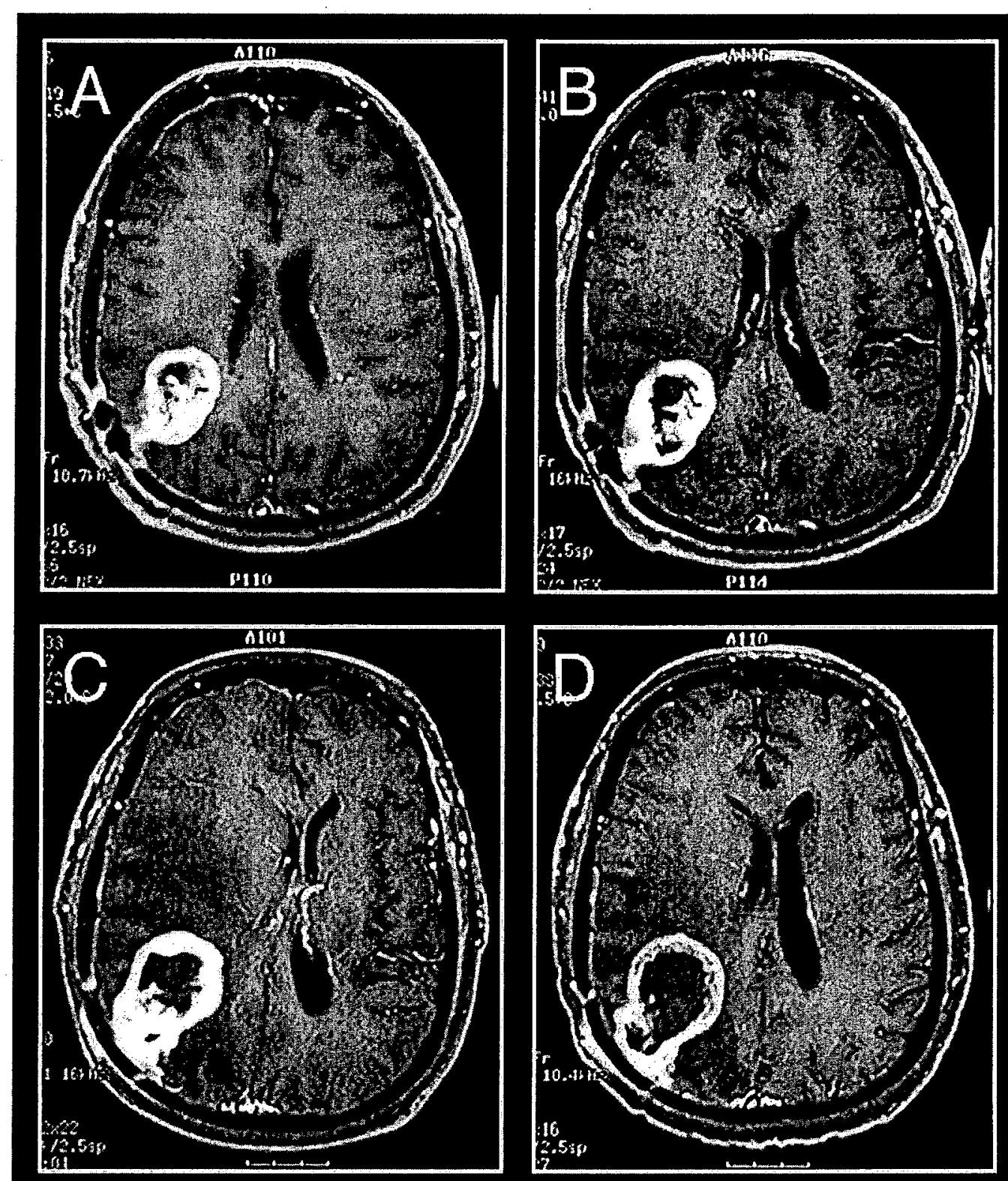

Figure 3. Serial MRI images for a representative patient

PET derived treatment plans indicate a significantly higher tumor dose that falls off much more rapidly than previously predicted. This rapid fall off in the BNCT radiation dose suggests that the dose to the edematous region is insufficient to kill the tumor cells in the edematous region around the tumor. This leads to inadequate treatment for an infiltrative tumor such as a GBM and has important implications for 
other tumors that might be amenable to BNCT. This inadequate radiation dose could be due to an inadequate BPA concentration or to the lack of near neighbor effects which would increase the total radiation dose to a given cell. BNCT performed with BPA would appear to be best suited for tumors such as metastatic malignant melanoma, which grow by direct extension rather than infiltration.

\section{B. New Boronated Agents for Potential Use in BNCT}

We were able to carry out a serial PET investigation on a Post-BNCT patient using both ${ }^{18} \mathrm{~F}$-BPA and a carbon-11 labeled aminocyclobutanecarboxylic and, ${ }^{11} \mathrm{C}$ $A C B C$. This agent is one member of a family of positron labeled, unnatural, cyclic amino acids that have been under development at The University of Tennessee Medical Center for use in imaging tumors. In a series of experimental clinical investigations, we have found that the four membered ring, $A C B C$, has proven to be quite effective for imaging brain tumors.

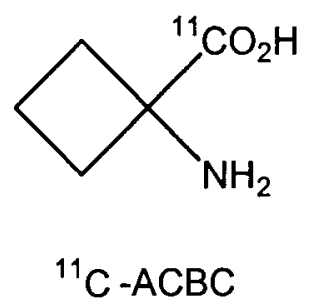

We were able to compare ${ }^{11} \mathrm{C}-\mathrm{ACBC}$ in a post BNCT patient who had also been imaged with ${ }^{18} \mathrm{~F}-\mathrm{BPA}$ a few days earlier. The results were striking in that the PET scans revealed that ${ }^{11} \mathrm{C}-\mathrm{ACBC}$ was as tumor selective as ${ }^{18} \mathrm{~F}-\mathrm{BPA}$ as can be seen in Figure 4. The selectivity of ${ }^{11} \mathrm{C}-\mathrm{ACBC}$ led us to prepare a series of boronated $\mathrm{ACBC}$ analogues. 
26yr Male GBM Tumor Comparative PET Tracers Axial Planes

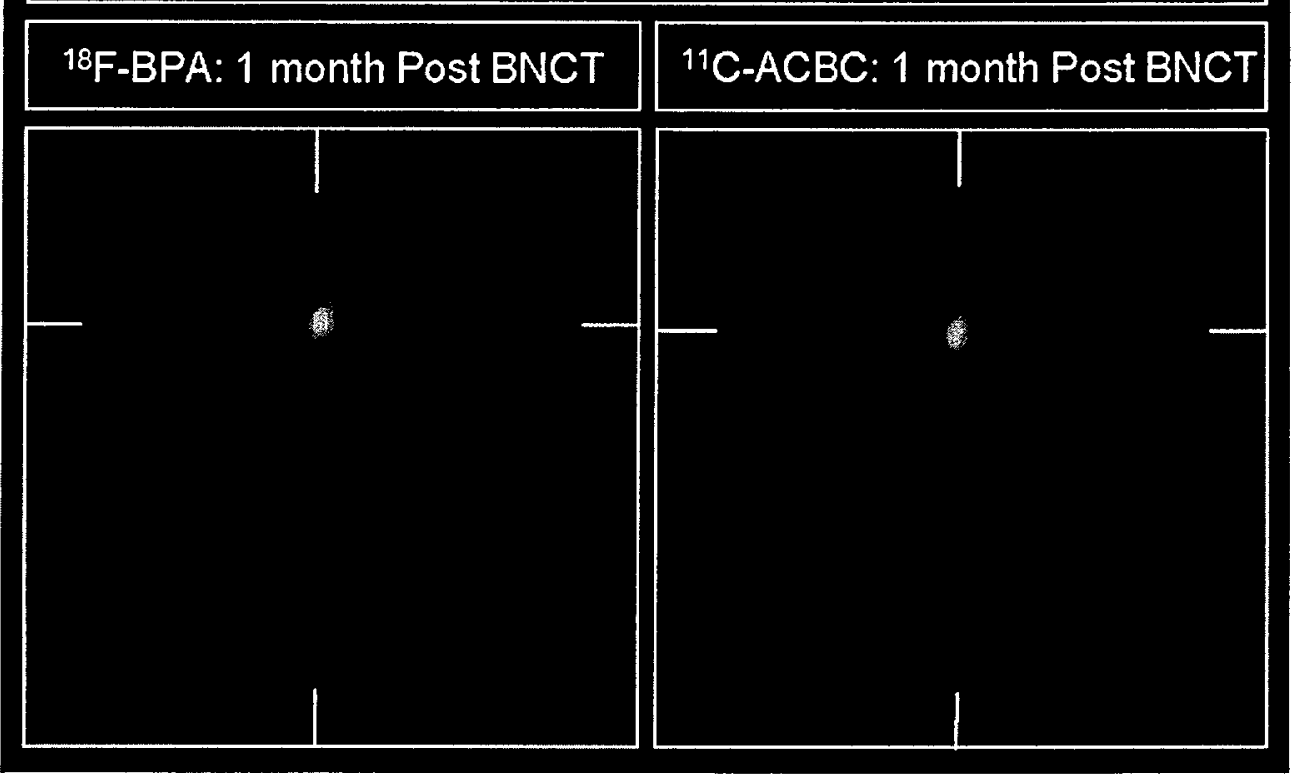

Figure 4. PET scans of Post-BNCT Patient Using ${ }^{18} \mathrm{~F}-\mathrm{BPA}-$ Fructose (left) and ${ }^{11} \mathrm{C}-\mathrm{ACBC}$ (right).

The effectiveness of carbon-11 labeled aminocyclobutanecarboxylic acid $(A C B C)$ in localizing in GBM tumors led us to investigate its potential use in BNCT. We targeted a series of boronated $A C B C$ derivatives with side chains that contained either single or multiple boron atoms. We initiated the study with the syntheses of carborane substituted ACBC derivatives. There are three isomers of carborane (ortho, meta, and para) each containing ten boron atoms. They differ only in the location of the two carbon atoms.
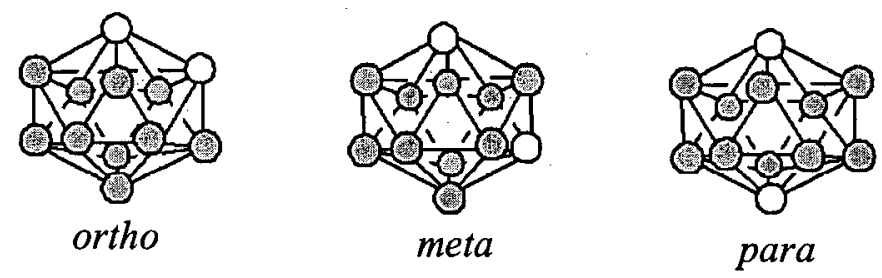

[Where $:=\mathrm{BH}, \mathrm{O}=\mathrm{CH}$ ] 
We first synthesized a carboranyl substituted 1-aminocyclobutanecarboxylic acid, 2

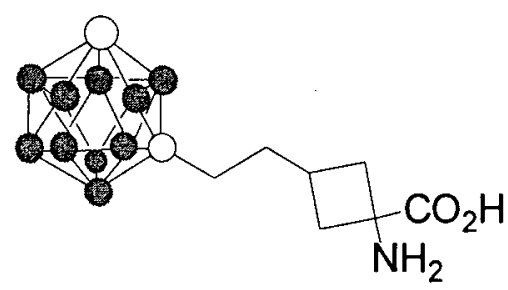

2

The compound was evaluated in vitro with respect to toxicity and cellular uptake. The toxicity studies were carried out in A549 human cancer cell cultures and revealed that cell growth was not suppressed at boron levels up to 10 micrograms of boron per $\mathrm{ml}$ of suspension over a period of 24 hours. The boron uptake in the cells was determined by inductively coupled plasma mass spectroscopy and were found to be on the order of $250 \mathrm{ng}$ of boron per cell which far exceeds the cellular boron concentration obtained in similar experiments utilizing BPA (on the order of $10 \mathrm{ng}$ of boron per cell), which compares favorably with values reported for porphyrin derivatives.

Preliminary biodistribution studies using mice carrying transplanted gliomas were hampered by the high lipophilicity of the carboranyl $A C B C$. To enhance solubility we synthesized a nido-meta-carboranyl ACBC. The compound was injected into nu/nu mice which had been implanted with a human glioblastoma tumor. The preliminary biodistribution data were rather remarkable in that the tumor to normal brain tissue uptake was greater than twice that observed for BPA (Table 1) 
Table 1: IN VIVO STUDY OF 1-AMINO-3-[2-(7-(2-hydroxyethyl)-1,7-dicarba-nidododecacaboran(12)-1-yl)ethyl]cyclobutanecarboxyli

Molecular formula: $\mathrm{C}_{11} \mathrm{H}_{26} \mathrm{~B}_{9} \mathrm{O}_{3} \mathrm{~N} \mathrm{Na}$

Formula weight: 349.2

\% of Boron: 28.57

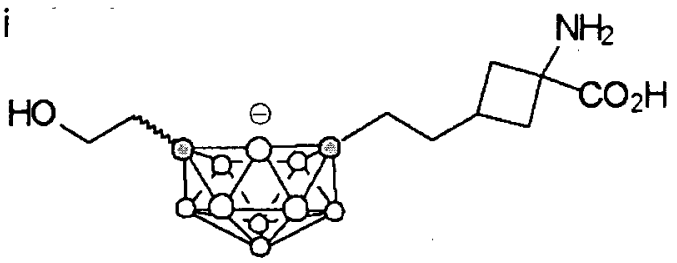

Concentration of drug injected: $6 \mathrm{mg} / \mathrm{mL} ; 1.71 \mathrm{mg} \mathrm{B} / \mathrm{mL} ; 1714 \mathrm{ppm}$ of $\mathrm{B} / \mathrm{mL}$

Boron analyses of the tissue samples

\begin{tabular}{|c|c|c|c|c|c|c|c|c|c|}
\hline \multirow{2}{*}{$\begin{array}{l}\text { Mice } \\
\#\end{array}$} & \multirow{2}{*}{$\begin{array}{l}\text { Gender } \\
\text { Nu/nu }\end{array}$} & \multirow{2}{*}{$\begin{array}{l}\text { Weight } \\
\text { (g) }\end{array}$} & \multirow{2}{*}{$\begin{array}{l}\text { Volume } \\
\text { injectd } \\
(\mathrm{mL})\end{array}$} & \multirow{2}{*}{$\begin{array}{l}\text { Boron } \\
\text { (ppm) } \\
\text { whole } \\
\text { body }\end{array}$} & \multirow{2}{*}{$\begin{array}{l}\text { Sacrifice } \\
\text { time (h) }\end{array}$} & \multicolumn{4}{|c|}{ Boron (ppm) in } \\
\hline & & & & & & Tumor & Brain & Blood & Muscle \\
\hline 1 & Male & 16.7 & 1 & 102.65 & 3 & $\begin{array}{l}51.7 \\
51.5\end{array}$ & 7.6 & --- & 37.4 \\
\hline 2 & Male & $\overline{19.4}$ & 1 & 88.36 & 6 & $\begin{array}{l}7.1, \\
8.8\end{array}$ & 1.5 & 29.8 & 5.1 \\
\hline 3 & Male & 11.6 & 0.5 & 39.86 & 12 & $\begin{array}{l}36.8, \\
29.8 \\
\end{array}$ & 3.7 & - & 20.1 \\
\hline 4 & Male & 21.5 & 0.5 & 73.89 & 24 & $\begin{array}{l}1.3, \\
1.1\end{array}$ & 0.5 & 1.3 & 0.7 \\
\hline
\end{tabular}

Unfortunately, the data were inconsistent which can be attributed to the ionic nature of the nido-carborane cage. It is known that ionic-carborane derivatives can react with proteins resulting in nonspecific binding to biological materials. To obviate the possibility that the nido-carborane was the source of the biological inconsistencies, we then synthesized hydroxy derivative (3) that we postulated would be less lipophilic than the initially prepared meta-carboranyl $A C B C$ derivative. Once again the biological studies were hampered by the poor water solubility of the meta-carborane moiety.

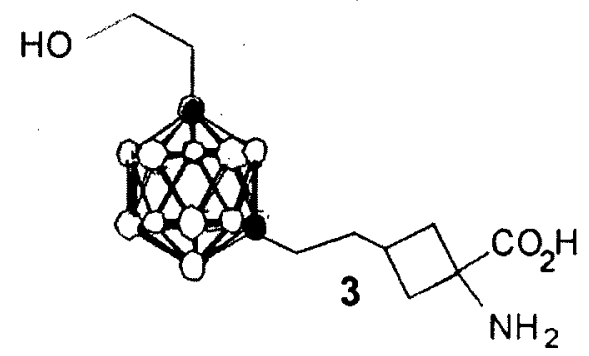


More recently, we prepared two polyol substituted carboranyl ACBC derivatives. The cascade polyol 4 appeared promising in that it was quite soluble (>60 g/liter).

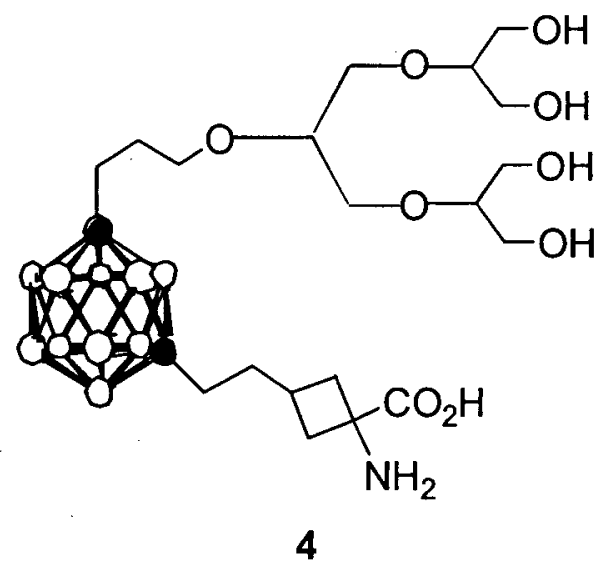

Unfortunately, in vivo tests in mice revealed unexpected toxicity. We then prepared a carbohydrate derivative 5 containing a galactose fragment.

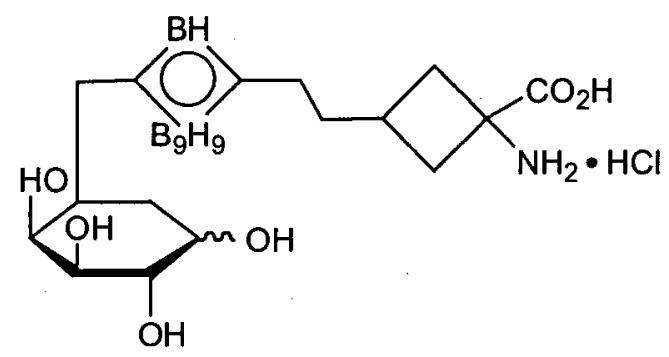

5

This compound demonstrated no toxicity in beast cancer cells. In this test, A435 cancer cells were grown in Leibovitz's $(L-15)$ minimum essential medium containing various concentrations of the boronated amino acids. The 2000 cells were then plated allowed to grow for a week and the colonies were counted and compared to control colonies. Within experimental error, the number of colonies was identical for the control and for the boron-containing cells. The compound will be tested in mice containing human transplanted to tumors by our colleagues at Washington State University..

We synthesized a boronic acid derivative of $A C B C$. The first reagent proved to be quite promising in that the tumor-normal tissue selectivity remained excellent and the blood values decreased dramatically. 
Table 2: In Vivo Study of a Boronic Acid Derivative of ACBCMolecular Formula: $\mathrm{C}_{8} \mathrm{H}_{14} \mathrm{BNO}_{5}$ Formula Weight: 215

$\%$ of Boron: $5.03 \%$

Concentration: $1.8 \mathrm{mg} \mathrm{B/mL}\left(\mathrm{H}_{2} \mathrm{O}\right)$

Injection: $0.3 \mathrm{~mL}$

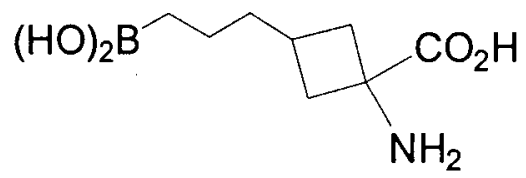

Mice: $20 \mathrm{~g} \mathrm{nu} / \mathrm{nu}$

\begin{tabular}{|l|l|l|l|l|l|}
\hline Mouse \# & Sac time, hr & $\begin{array}{l}\text { ppmB } \\
\text { Tumor }\end{array}$ & ppm B Brain & $\begin{array}{l}\text { ppm } \\
\text { Blood }\end{array}$ & $\begin{array}{l}\text { ppm } \\
\text { Muscle }\end{array}$ \\
\hline A1 & 1 & 5.7 & 0.9 & 8.5 & 3.9 \\
\hline A2 & 1 & 6.3 & 1.5 & 7.3 & 11.1 \\
\hline A3 & 3 & 2.5 & 0.8 & 1.1 & 1.2 \\
\hline A4 & 3 & 4.0 & 1.3 & 1.9 & 1.9 \\
\hline A5 & 6 & 5.3 & 1.1 & 1.2 & 1.8 \\
\hline A6 & 6 & 5.4 & 1.3 & 1.4 & 2.0 \\
\hline
\end{tabular}

We also prepared a series of para-boronophenyl derivatives of $A C B C, 6-9$. The<smiles>NC1(C(=O)O)CC(Cc2ccc([18OH])cc2)C1</smiles>

$$
\begin{aligned}
& 6, n=0 \\
& 7, n=2 \\
& 8, n=3 \\
& 9, n=7
\end{aligned}
$$


materials were shown to be non toxic to the A435 cells in the in vitro tests. Unfortunately, the molecules exhibited poor solubility and tests in mice bearing human melanoma tumors were inconclusive. Fructose complexes of these reagents will be prepared and sent to Washington State University for further in vivo testing.

More recently, a series of related cyclic am ino acids have been prepared. These agents have also demonstrated little toxicity in in vitro cell cultures. Their

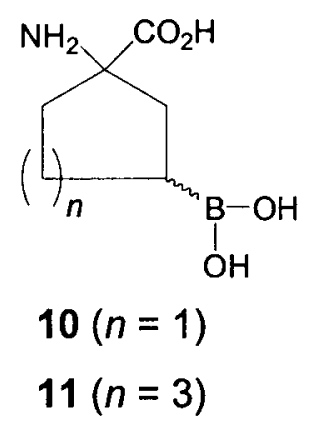

fructose complexes will be prepared and sent for in vivo analyses in mice bearing human melanoma tumors. The tests will be carried out in collaboration with our colleagues at Washington State University and INEEL. 


\section{BIBLIOGRAPHY OF DOE PUBLICATIONS}

\section{A. Journal Articles}

1. Nichols, T. L.; Kabalka, G. W.; Busse, P. M.; Smith, G. T.; Miller, L. W.; Khan, M. $\mathrm{K}$. "The Use of ${ }^{18} \mathrm{~F}$-para-boronophenylalanine to Image Metastic Malignant Melanoma with Positron Emission Tomography." J. Neuro. Oncol. 2003, 62, 187.

2. Nichols, T. L.; Kabalka, G. W.; Miller, L. F.; Khan, M.; Wyatt, M.; Smith, G. T.; Longford, C.P.D. "Improved Treatment Planning for Boron Neutron Capture Therapy for Glioblastoma Multiforme Using Fluorine-18 Labelled paraBoronophenylalanine and Positron Emission Tomography" Med. Phys. 2002, 29 , 2351.

3. Kabalka, G. W.; Bollu, V.; Das, B. C. "Allylboration of Carbonyl Compounds in Ionic Liquid" Green Chem. 2002, 4, 472.

4. Nichols, T. L.; Kabalka, G. W.; Miller, L. F.; Khan, M.; Wyatt, M.; Smith, G. T.; Longford, C.P.D. "Improved Treatment Planning for Boron Neutron Capture Therapy for Glioblastoma Multiforme Using Fluorine-18 Labelled paraBoronophenylalanine and Positron Emission Tomography" Med. Phys. 2002, 29, 2351.

5. Kabalka, G. W.; Bollu, V.; Das, B. C. "Allylboration of Carbonyl Compounds in Ionic Liquid" Green Chem. 2002, 4, 472.

6. Kabalka, G. W.; Das, B. C.; Das, S.; Li, G.; Srivastava, R. R.; Natarajan, N. "Synthesis of 1-Amino-3-\{2-[7-(6-deoxy- $\alpha / \beta-D-g a l a c t o p y r a n o s e-6-y l)-1,7-d i c a r b a-$ closo-dodecarboran-1-yl]ethyl\}cyclobutanecarboxylic Acid Hydrochloride". Collect. Czech. Chem. Comm. 2002, 67, 836.

7. Chandra, S.; Kabalka, G. W.; Lorey, D. R.; Smith, D. R.; Coderre, J. A. "Imaging of Fluorine and Boron from Fluorinated-boronophenylalanine in the Same Cell at Organelle Resolution by Correlative Ion Microscopy and Confocal Laser Scanning Microscopy", Clin. Cancer. Res. 2002, 8, 2675. 
8. Kabalka, G. W.; Das, B. C.; Das, S. "Rhodium Catalyzed 1,4-Addition Reactions of Diboron Reagents to Electron Deficient Olefins." Tetrahedron Lett. 2002, 43, 2323.

9. Kabalka, G. W.; Nichols, T. L.; Akula, M.; Longford, C.P.D.; Miller, L. "Synthesis of Carbon-11 Labeled para-Boronophenylalanine for Boron Neutron Capture Therapy and Their use in PET Based Treatment Planning." in Synthesis and Applications of Isotopically Labelled Compounds, Proceedings of the International Symposium, $7^{\text {th }}$. Pleiss, U.; Voges, R. (Eds), John Wiley and Sons, Chichester, UK, 2001, 329-332.

10. Kabalka, G. W.; Das, B.; Das, S. "Synthesis of Novel Boron Containing Unnatural Cyclic Amino Acids As Potential Therapeutic Agents." Tetrahedron Lett $.2001,42,7145$.

11. Kabalka, G. W.; Malladi, R. R. "A New Synthesis of Alkenes via a Boron Trifluoride Mediated Reaction of Aliphatic Ketones with Aromatic Ketones." J. Chem. Res. 2001, 57, 8017.

12. Kabalka, G. W.; Das, B.C.; Das, S.; Li, G.; Bao, W. "Synthesis of a Water Soluble Carborane Containing Amino Acid as a Potential Therapeutic Agent." Synlett. 2001, 1419.

13. Byrne, T.E.; Miller, L.F.; Kabalka, G.W.; Martin, R.C. "A New Simplified System for the Evaluation of BNCT Pharmaceuticals," Frontiers in Neutron Capture Therapy, Hawthorne, M.F. and Wiersma, R.M. (Eds), Plenum Press, New York, 2001, 955.

14. Kabalka, G. W.; Smith, G. T.; Nichols, T.L.; Dyke, J.P.; Longford, P.D.; Hubner, K.F. "The Role of Dynamic Positron Emission Tomography for Quantifying Boron-10 In Vivo Using the Fructose Complex F-18 Labeled Boronophenylalanine PET," Frontiers in Neutron Capture Therapy, Hawthorne, M.F. and Wiersma, R.M. (Eds), Plenum Press, New York, 2001, 853. 
15. Nichols, T.L.; Kabalka, G.W.; Smith, G. T.; Dyke, Longford, P.D.; Hubner, K.F. "Treatment Planning Based on Dynamic Positron Emission Tomography for Boron Neutron Capture Therapy for Glioblastoma Multiforme," Frontiers in Neutron Capture Therapy, Hawthorne, M.F. and Wiersma, R.M. (Eds), Plenum Press, New York, 2001, 185.

16. Kabalka, G. W.; Li, G.; Srivastava, R.R. "A Potential New BNCT Agent: Galactose Containing 1-Amino-3-[2-(1,7-Dicarbra-closo-Dodecaboran(1-yl)Ethyl]Cyclobutanecarboxylic Acid," in Frontiers in Neutron Capture Therapy, Hawthorne, M.F. and Wiersma, R.M. (Eds), Plenum Press, New York, 2001, 803.

17. Bendel, P.; Anderson, C.; Kabalka, G.W. "Structure of the BPA-Fructose Complex: A C-13 NMR Investigation," in Frontiers in Neutron Capture Therapy, Hawthorne, M.F. and Wiersma, R.M. (Eds), Plenum Press, New York, 2001, 869.

18. Srivastava, R. R.; Das, B. C.; Longford, C. P. D.; Kabalka, G. W. "The Development of Boron Neutron Capture Therapy Agents Utilizing Positron Emission Tomography," in Contemporary Boron Chemistry, Hughes, A.K.; Davidson, M. (Eds.) Royal Society of Chemistry, Cambridge, United Kingdom, $2000,121$.

19. Kabalka, G. W:; Reddy, N. K.; Wang, L., Malladi, R. F., "Synthesis of 4-Borono2-Fluorophenylalanine" Org. Prep. Proc. Intl. 2000, 32, 29.

20. Das, B.C.; Kabalka, G. W.; Srivastava, R. R.; Bao, W.; Das, S. "Synthesis of a Water Soluble Boron Neutron Capture Therapy Agent: 1-Amino-3-[2-(7-\{3-[2-(2hydroxymethyl-ethoxy)-1-(2-hydroxy-1-hydroxymethyl-ethoxymethyl)ethoxy]propyl\}-1,7-di-carba-closo-dodecaboran-1-yl)ethyl]cyclobutanecarboxylic Acid." J. Organomet. Chem. 2000, 614-615, 255.

21. Kennel, S. J.; Davis, I. A.; Branning, J.; Pan, H.; Kabalka, G. W.; Paulus, M. J. "High Resolution Computed Tomography and MRI for Monitoring Lung Tumors," Med. Phys., 2000, 27, 1101. 
22. Panov, V.; Solomon, Y.; Kabalka, G. W.; Bendel, P. "Uptake and Washout of Borocaptate Sodium and Boronophenylalanine in Cultured Melanoma Cells: A Multinuclear NMR Study" Radiat. Res. 2000, 154, 104.

23. Kabalka, G. W.; Yang, K.; Wang, Z. "The Reaction of $\alpha$-Ketoacids with Allylboronates," in Contemporary Boron Chemistry, Hughes, A.K.; Davidson, M. (Eds.) Royal Society of Chemistry, Cambridge, United Kingdom, 2000, 454.

24. Kabalka, G. W.; Srivastava, R. R.; Das, B.C.; Nichols, T. L.; Smith, G. T. "The Development of Boron Neutron Capture Agents Utilizing Positron Emission Tomography," in Contemporary Boron Chemistry, Hughes, A.K.; Davidson, M. (Eds.) Royal Society of Chemistry, Cambridge, United Kingdom, 2000, 120.

25. Yu, S.; Li, N.-S.; Kabalka, G. W. "Stereoselective Synthesis of Highly Functionalized Trisubstituted Olefins via the Aldol Reaction of Allenoxyborinates with Carbonyl Compounds," J. Org. Chem. 1999, 64, 5822.

26. Srivastava, R. R.; Singhaus, R.; Kabalka, G. W. "4-Dihydroxyborylphenyl Analogues of 1-Aminocyclobutanecarboxylic Acids: Potential Boron Neutron Capture Therapy Agents," J. Org. Chem. 1999, 64, 8495.

27. Li, G.; Kabalka, G.W. "Application of 1,2:5,6-di-O-Cyclohexylidene-D-mannitol As the Chiral Director in Matteson's Asymmetric Homologation," J. Organomet. Chem. 1999, 581, 66.

B. Research Presentations

1. "Use of PET for In Vivo Boron Neutron Capture Therapy Dose Planning Using F18 Boronophenylalanine Fructose." G. T. Smith, G. W. Kabalka, T. L. Nichols, L. R. Miller. Academy of Molecular Imaging National Meeting, SanDiego, CA (October, 2002).

2. "The Dependence of the Microscopic Dose in Boron Neutron Capture Therapy on Cell Geometry and Boron Content." T. Nichols, L. Miller, G. Kabalka. The Tenth 
International Symposium on Neutron Capture Therapy for Cancer, Essex Germany (Sept, 2002).

3. Effects of Boron Self Shielding on BNCT Tumor Dose." A. Rahim, M. Khan, L. Miller, T. Nichols, G. W. Kabalka. The Tenth International Symposium on Neutron Capture Therapy for Cancer, Essen Germany (Sept, 2002).

4. "An Analysis of the Biodistribution of BNCT Pharmaceuticals with Laser Induced Breakdown Spectroscopy (LIBS)." T. E. Byrne, M. K. Khan, G. W. Kabalka, M. Martin. The Tenth International Symposium on Neutron Capture Therapy for Cancer, Essen Germany (Sept, 2002).

5. "Synthesis and Preliminary Evaluation of Boronated Amino Acids for Use In BNCT." G. W. Kabalka, N. Natarajan, Z. Wu, J. Green, M. Yao, M. Khan. The Tenth International Symposium on Neutron Capture Therapy for Cancer, Essen Germany (Sept, 2002).

6. "Biokinetics of Various Infusion Protocols for Neutron Capture Therapy" L. F. Miller, A. Rahim, M. Khan, T. Nichols, G. W. Kabalka. The Tenth International Symposium on Neutron Capture Therapy for Cancer, Essen Germany (Sept, 2002).

7. "Synthesis Of Novel Boron Containing Unnatural Cyclic Amino Acids As Potential Therapeutic Agents." G. W. Kabalka, N. Natarajan, B. C. Das, S. Das The Eleventh International IMEBORON Symposium, Moscow Russia (August, 2002).

8. "Improving Existing BNCT Radiation Dosimetry By Use of Registered ${ }^{18} \mathrm{~F}-\mathrm{BPA}$ PET and T1-Weighted Images." M. K. Khan, L. F. Miller, A. A. Rheem, G. W. Kabalka, T. F. Nichols, RPSD Meeting, Santa Fe, NM (April, 2002).

9. "Synthesis of Novel Boronic Acid Containing Unnatural Cyclic Amino Acids As Potential BNCT agents" G. W. Kabalka, B. C. Das, S. Das. $212^{\text {th }}$ ACS National Meeting, Chicago, IL (August, 2001).

10. "Use of Positron Emission Tomography for Determination of Cellular-Level Kinetics." L. F. Miller, T. L. Nichols, M. Khan, G. W. Kabalka, A. Rahim, G. T. 
Smith, A. I. Apostoaei, C. A. Large. $13^{\text {th }}$ Symposium on Microdosimetry, Stresa, Italy (June, 2001).

11. "The Development of PET Labelled Agents in Cancer Treatment Planning." G. W. Kabalka, Pacifichem 2000, Honolulu HI (December, 2000).

12. "Positron Emission Tomography Based Dosimetry for Boron Neutron Capture Therapy." L. F. Miller, M. K. Khan, G. W. Kabalka, T. L. Nichols, G. T. Smith, A. Rahim, M. S. Wyatt, A. I. Apostoaei, C. A. Large American Nuclear Society. Washington, D.C. (November, 2000).

13. "Use of Positron Emission Tomography for Determination of Tissue Specific Kinetics." L. F. Miller, G. Kabalka, M. Khan, A. Rahim, T. Nichols, M. Wyatt, J. Thie, G. Smith, and I. Apostoaei. The Ninth International Symposium on Neutron Capture Therapy for Cancer. Osaka, Japan (October, 2000).

14. "The Development and Preliminary Testing of New Boronated Agents for BNCT Based on PET Derived Data" T. L. Nichols, G. W. Kabalka, M. Kahn, B. Das, S. Das, L. Miller. The Ninth International Symposium on Neutron Capture Therapy for Cancer. Osaka, Japan (October, 2000).

15. "Positron Emission Tomography Based Dosimetry for Boron Neutron Capture Therapy" L. F. Miller, G. W. Kabalka, M, K. Khan, G. T. Smith, A. Rahim, M. S. Wyatt, A. I. Apostoaei, C. A. Large. The Ninth International Symposium on Neutron Capture Therapy for Cancer. Osaka, Japan (October, 2000).

16. "The Use of Positron Emission Tomography in BNCT Treatment Planning for Metastatic Malignant Melanoma and Glioblastoma Multiforme" G. W. Kabalka, T. Nichols, G. Smith, L. Miller and M. Kahn. The Ninth International Symposium on Neutron Capture Therapy for Cancer. Osaka, Japan (October, 2000).

17. "Identification of Biokinetic Parameters for Boron Neutron Capture Therapy". L. F. Miller, G. W. Kabalka, M. Khan, A. Rahim, and T. Nichols. Proceedings of the American Nuclear Society and Health Physics Society Conference on Radiation 
Protection for Our National Priorities: Medicine, The Environment and the Legacy, Spokane, Washington (September, 2000).

18. "Use of Radiolabeled Positron Emission Tomography to Improve Dosimetry for Boron Neutron Capture Therapy." M. K. Kahn, L. F. Miller, G. W. Kabalka and T. F. Nichols, Radiation Protection and Shielding Annual Meeting, Seattle, Washington (September, 2000).

19. "The Use of Positron Emission Tomography in the Design and In Vivo Detection of New Drugs" G. W. Kabalka. Gordon Conference on Drug Metabolism, Plymouth, New Hampshire (July, 2000).

20. "The Use of Positron Emission Tomography in Treatment Planning for Neutron Capture Therapy." G. W. Kabalka and L. Miller. Idaho National Engineering and Environmental Laboratory, Idaho Falls, Idaho (July, 2000).

21. "Determination of Tissue Specific Kinetics to Improve Boron Neutron Capture Therapy." L. F. Miller, G. W. Kabalka, M. Khan, A. Rahim, T. Nichols, J. Thie, G. T. Smith. Annual Meeting of the Health Physics Society, Denver, CO (June, 2000).

22. "Synthesis of Novel Boronic Acid Containing Analogues of Tumor Seeking Unnatural Amino Acids: As Potential BNCT Agents" G. W. Kabalka, B. Das, R. R. Srivastava, S. Das, W. Bao. BUSA VII Pittsburgh, PA, (June, 2000).

23. "Synthesis of Carbon-11 and Fluorine-18 Labeled para-Boronophenylalanine and Their Use in PET -Based Treatment Planning for Boron Neutron Capture Therapy." G. W. Kabalka, T. L. Nichols, C.P.D. Longford, G. T. Smith. International Isotope Meeting, Dresden Germany (June, 2000).

24. "Synthesis of Carbon-11 and Fluorine-18 Labeled para-Boronophenylalanine and Their Use in PET-based Treatment Planning for Boron Neutron Capture Therapy" G. W. Kabalka, T. L. Nichols, C.P.D. Longford, G. T. Smith. Third Annual Medical Center Research Day, Knoxville, TN (May, 2000). 
25. "F-18 BPA for BNCT of Melanoma" G. W. Kabalka, T. L Nichols, C.P.D. Longford, G. T. Smith. Third Annual Medical Center Research Day, Knoxville, TN (May, 2000).

26. "The Development of Boron Neutron Capture Agents Utilizing Positron Emission Tomography" G. W. Kabalka, R. R. Srivastava, B. C. Das, T. L. Nichols, G. T. Smith. ACS Southeastern Regional Meeting. Knoxville, TN (October, 1999).

27. "Synthesis of 4-dihydroxyborylphenyl analogues of 1-aminocyclobutanecarboxyl acid: Potential BNCT agents" G. W. Kabalka, R. R. Srivastava, R. R. Singhaus. ACS Southeastern Regional Meeting. Knoxville, TN (October, 1999).

28. "Synthesis of a Cascade Polyol-Containing Meta-Carboranyl-1aminocyclobutane-carboxylic Acid as a Potential BNCT Agent" G. W. Kabalka, R.R. Srivastava, G. Li, B.C. Das. ACS National Meeting. New Orleans, LA (August, 1999).

29. "Synthesis of Carbon-11 Labeled 4-boronophenylalanine: a Pet Agent For Use in BNCT Treatment Planning" R. R. Srivastava, B. C. Das, C.P.D. Longford, and G. W. Kabalka. The Xth International Conference on the Chemistry of Boron. Durham, UK (July, 1999).

30. "The Development of Boron Neutron Capture Agents Utilizing Positron Emission Tomography" G. W. Kabalka, R. R. Srivastava, B. C. Das, T. L. Nichols and G. T. Smith. The Xth International Conference on the Chemistry of Boron. Durham, UK (July, 1999).

31. "Uptake and Washout of Borocaptate Sodium (BSH) and Borono-phenylalanine (BPA) in Melanoma Cells: An In-Vitro Multinuclear NMR Study." V. Panov, Y. Salomon, G.W. Kabalka, P. Bendel. International Meeting of the Society Magnetic Resonance Imaging in Medicine. Cambridge, England (July, 1999).

32. "Synthesis of Fluorine-18 Labeled 1-Amino-3-(4-dihydroxyborylphenyl) cyclobutanecarboxylic Acid: a Pet Agent for Use in BNCT Treatment Planning." 
R. R. Srivastava, C.P.D. Longford, and G. W. Kabalka, $13^{\text {th }}$ International Symposium of Radiopharmaceutical Chemistry; St. Louis, MO (July, 1999).

33. "BNCT Dosimetry Calculations Utilizing PET Input" L. F. Miller, G. W. Kabalka, G. T. Smith, Idaho National Engineering Laboratory. Idaho Falls, ID (July, 1999).

34. "Use of PET to Improve Dosimetry for BNCT", M. Khan, L. F. Miller, G. W. Kabalka, T. L. Nichols, American Nuclear Society. Boston, MA (June, 1999).

35. "The First Use of ${ }^{18} \mathrm{~F}$-para-Boronophenylalanine for Imaging Metastatic Malignant Melanoma Using Positron Emission Tomography" G.W. Kabalka, T.L. Nichols, G.T. Smith, K.F. Hubner, C.P.D. Longford, Second Tennessee Conference on Biomedical Engineering. Nashville, TN (June, 1999).

36. "Uptake and Washout of Borocaptate Sodium (BSH) and Borono-phenylalanine (BPA) in Melanoma Cells: An In Vitro Multinuclear NMR Study." V. Panov, Y. Solomon, G.W. Kabalka, Peter Bendel. International Society for Magnetic Resonance in Medicine, (June, 1999).

37. "Comparisons of Dosimetry for Boron Neutron Capture Therapy." M. Khan, L. Miller, G. W. Kabalka, T. L. Nichols, G. T. Smith. American Association of Physicist in Review Meeting Nashville, TN (Medical Physics, Vol. 26, No. 5, June, 1999).

38. "Use of PET to Improve Dosimetry for BNCT." L. F. Miller, G. W. Kabalka, T. L. Nichols. American Nuclear Society 1999 Annual Meeting, Boston, MA (June, 1999).

39. "The Role of Dynamic Positron Emission Tomography for Quantifying Boron-10 In Vivo Using the Fructose Complex of F-18 Labeled Boronophenylalanine." George W. Kabalka, Gary T. Smith, Trent L. Nichols, Jon P. Dyke, C.P.Desmond Longford, Karl F. Hubner, Murthy Akula and George W. Kabalka. Joint Institute for Biological Sciences (JIBS) and Graduate Program for Genome Science and Technology Colloquium, Knoxville, TN (May, 1999). 


\section{Invited Lectures}

1. "Organometallic Halides in Organic Syntheses," University of Puerto Rico, San Juan, Puerto Rico (October, 2002).

2. "The Use of Boron Halides in Organic Synthesis," Purdue University, West Layette, IN (March, 2002).

3. "The Use of Positron Tomography for Treatment Planning in BNCT", Atomic Energy Commission, Buenos Aries, Argentina (November, 2001).

4. "The Development of Pharmaceuticals for Use in the Detection of Cancer", University of North Carolina, Asheville, NC (October, 2001).

5. "The Use of PET in Cancer Therapy, University of Helsinki, Helsinki, Finland (September, 2001).

6. "The Use of PET in BNCT Treatment Planning" University of Uppsala, Uppsala Sweden (September, 2001).

7. "The Use of PET in Drug Design," G. W. Kabalka, Galaxo-Smith Kline Pharmaceuticals, Philadelphia, PA (February, 2001).

8. "The Development of PET Labelled Agents in Cancer Treatment Planning." G. W. Kabalka, Pacifichem 2000, Honolulu, HI (December, 2000).

9. "Development of PET Labeled Agents for Cancer Treatment", Pacifichem, Honolulu, HI (December, 2000).

10. "The Use of Boron and Tin in Nuclear Medicine", DOE Symposium, Williamsburg, VA (October, 2000).

11. "Incorporation of Radiohalogens Via Organoborane, Organotin, and Related Reagents." G. W. Kabalka. Fourth International Symposium on Radiohalogens. Whistler, BC Canada, (September, 2000).

12. "The Development of New Agents for BNCT", Idaho National Engineering Laboratory, Idaho Falls, ID (July, 2000). 
13. "Positron Emission Tomography as a Tool for the Development and Evaluation of New Drugs", G. W. Kabalka. Gordon Conference on Drug Metabolism, Plymouth, New Hampshire (July, 2000).

14. "The Use of PET and MRI for BNCT Treatment Planning", The National Cancer Institute, Rockville, MD (June, 2000).

15. "The Use of Positron Tomography in the Development of New Chemotherapeutic Agents", The Seventh International Isotope Meeting", Dresden, Germany (June, 2000).

16. "New Boronated Agents for Neutron Capture Therapy" Symposium on Neutron Capture Therapy, Knoxville, TN (February, 2000).

17. "Development of BNCT Imaging Agents", Air Force Radiological Research Institute, Bethesda, MD (February, 2000).

18. "Design and Synthesis of Diagnostic Pharmaceuticals." East Tennessee State University, Murfreesboro, TN (December, 1999).

19. "The Role of Chemistry in Medicine." Mexico City, Mexico (April 1999).

\section{GRADUATE AND POSTDOCTORAL STUDENTS}
A. Postdoctoral Students
B. Graduate Students
Dr. James Green
George Pacer (M.S. 1999)
Dr. James Wu
Robert Singhaus (M.S. 1999)
Dr. Sasmita Das
Aaron Smith (Ph.D. Candidate, 2002)
Dr. Bhaskar Das
Muhammad Khan (Ph.D. Candidate, 2002)
Dr. Rajiv Srivastava
T rent Nichols (Ph.D. Candidate 2002)
Dr. Guishing Li
Nisha Natarajan (Ph.D. Candidate) 


\section{Undergraduate Students*}

Catherine Chidester; University of TN (1999)

Jordan Haney; Georga State Univ. (1999)

Sarah Trotman; University of TN (1999)

Nicie Conley; Tennessee State Univ. (2000)

Brad Collins, Cumberland College (2000)

Jason Susong; University of TN (2000)

Michael Finger; University of TN (2001)

MacShelle Steward; University of TN (2001)

John Holbrook; University of TN (2001)

David Spence; University of TN (2001)

Ha Tran; University of TN (2002)

Michelle Stephens; Trevecca Nazarene University (2002)

Michael Steiner; University of TN (2002)

Kate Wilson; University of TN (2002)

*Students from universities other than The University of Tennessee were summer research participants.

\section{REFERENCES}

1 Nigg, D. W. "Methods for Radiation Dose Distibution analysis and Treatment Planning In Boron Neutron Capture Therapy." Int. J. Radiat. Oncol. Biol. Phys. 1994, 28, 1121. 
2 Nigg, D. W.; Wheeler, F. J.; Wessol, D. E.; Capala, J.; Chadha, M. "Computational Dosimetry and Treatment Planning for Boron Neutron Capture Therapy. J. Neurooncol. 1997, 33, 93.

3 Busse, P. M.; Zamenhof, R. G.; Madoc-Jones, H.; Solares, G.; Kiger, W. W. III; Riley, K.; Chuang, C.; Rogers, G. S.; Harling, O. K. "Clinical Follow-Up of Patients with Melanoma of the extremity Treated in a Phase I Boron Neutron Capture Therapy Protocol." In: Larsson, B.; Crawford, J.; Weinrich R, (Eds.) Advances in Neutron Capture Therapy. Vol. 1 New York: Elsevier, pp. 60-64, 1997

4 Zamenhof, R.; Redmond, E. II; Solares, G.; Katz, D.; Riley, K.; Kiger, S.; Harling, O. "Monte Carlo-Based Treatment Planning for Boron Neutron Capture Therapy Using Custom Designed Models Automatically Generated from CT Data." Int. J. Radiat. Oncol. Biol. Phys. 1996, 35, 383.

5 Zamenhof, R. G. "Microdosimetry for Boron Neutron Capture Therapy: A Review." J. Neurooncol 1997, 33, 81.

6 Kabalka, G. W.; Smith, G. T.; Reid, W. S.; Longford, C. P. D.; Roberts, T. G.; Reddy, N. K.; Buonocore, E.; Hubner, K. F. "Evaluation of Fluorine-18-BPAFructose for Boron Neutron Capture Treatment Planning," J. Nucl. Med. 1997, $38,1762$.

7 Imahori, Y.; Ueda, S.; Ohmori, Y.; Kusuki, T.; Ono, K.; Fujii, R.; Ido, T. "Fluorine18-Labeled Fluoroboronophenylalanine PET in Patients with Glioma." J. Nucl. Med., 1998, 39, 1833.

8 Imahori, Y.; Udea, S.; Ohmori, Y.; Sakae, K.; Kusuki, T.; Kobayashi, T.;

Takagaki, JM.; Ono, K.; Ido, T.; Fujii, R. "Positron Emission Tomography-Based Boron Neutron Capture Therapy Using Boronophenylalanine for High-Grade Gliomas: Part II." Clin. Cancer Res. 1998, 4, 1833. 
9 Imahori, Y.; Ueda, S.; Ohmori, Y.; Sakae, K.; Kusuki, T.; Kobayaashi, T.;

Takagaki, M.; Ono, K.; Ido, T.; Fujii, R.; Ido, T.; Fluorine-18-Labeled

Fluoroboronophenylalanine PET in Patients with Glioma." J. Nucl. Med. 1998, 4, 1825.

10 Nichols, T. L.; Kabalka, G. W.; Miller, L. F.; Khan, M.; Wyatt, M.; Smith, G. T.; Longford, C.P.D. "Improved Treatment Planning for Boron Neutron Capture Therapy for Glioblastoma Multiforme Using Fluorine-18 Labelled paraBoronophenylalanine and Positron Emission Tomography" Med. Phys. 2002, 29, 2351.

11 Nigg, D. W. "The Validity of Post-Processing MCNP Results with Boron Concentations for BNCT Treatment Planning." In: Miller, L. F. (ed.) 1998.

12 Chanana, A. D.; Capala, J.; Chadha, M.; Coderre, J. A.; Diaz, A. Z.; Elowitz, E. H.; Iwai, J.; Joel, D. D.; Liu, H. B.; Ma, R.; Pendzick, N.; Peress, N.S.; Shady, M. S.; Slatkin, D. N.; Tyson, G. W.; Wielopolski, L. "Boron Neutron Capture Therapy for Glioblastoma Multiforme: Interim Results From The Phase I/II DoseEscalation Studies [In Process Citation]." Neurosurgery, 1999, 44 1182-1192; Discussion 1192-1183. 